\title{
Study of Genetic Divergence in Barnyard millet (Echinochloa frumentacea (Roxb.) Link) Germplasm
}

\author{
Rinkey Arya ${ }^{1 *}$, Arun Bhatt ${ }^{2}$ and Vineet Kumar ${ }^{3}$
}

${ }^{1}$ Dr Yashwant Singh Parmar University of Horticulture and Forestry Nauni Solan, H.P. (173 230), India

${ }^{2,3}$ V. C. S. G. Uttarakhand University of Horticulture and Forestry, Ranichauri, Uttarakhand (249 199), India

\section{Corresponding Author}

Rinkey Arya

e-mail: aryarinkey555@gmail.com

\author{
Article History \\ Article ID: 3 C0695 \\ Received in $27^{\text {th }}$ October, 2017 \\ Received in revised form $18^{\text {th }}$ December, 2017 \\ Accepted in final form $20^{\text {th }}$ March, 2018
}

\begin{abstract}
The present investigation was carried out for genetic divergence of barnyard millet (Echinochloa frumentacea (Roxb.) Link) germplasm during Kharif, 2014 at Research Block, Department of Crop Improvement and Seed Testing at Department of Seed Science and Technology, V. C. S. G. Uttarakhand University of Horticulture and Forestry, College of Forestry, Ranichauri (Uttarakhand) with 35 diverse genotypes as EC-134192, IC-543, EC-578, IEC-411, RAU-11, VL-222, IC-595, PRB-402, EC-756, RAU-2, VL-232, IEC-515, IC-542, IEC-111, TNAU-149, PRB-802, IEC-546, PRB-903, VL-174, IEC-523, PRB-401, IEC-566, IEC-513, PRB-904, VL-230, VL-239, TNAU-155, IEC-636, IEC-531, VL-182 and PRB-9402, of barnyard millet including three checks viz., VL-172, VL-207 and PRJ-1. In genetic divergence, all thirty-five genotypes were grouped by using Mahalanobis $D^{2}$ stastistic into 6 clusters irrespective of geographical diversity, indicating no parallelism between geographic and genetic diversity. The cluster pairs exhibiting very high inter-cluster distances were cluster IV and VI, cluster IV and V, cluster II and IV, cluster III and VI, cluster I and IV and cluster III and IV. Considering cluster mean and genetic distance the crossing between genotypes of clusters IV with genotypes of cluster $\mathrm{VI}$ and those genotypes of cluster $\mathrm{V}$ would be fruitful for obtaining transgrassive segregants for developing high yielding and better quality barnyard millet varieties.
\end{abstract}

Keywords: Barnyard millet, genetic divergenc, germplasm, mahalanobis $D^{2}$

\section{Introduction}

Barnyard millet (Echinochloa frumentacea (Roxb.) Link) $(2 n=4 x=36)$ also called as Jhangora, Sawanor Madirais largely a self-pollinated crop. Barnyard millet is mainly grown in India, China, Japan, and Korea for human consumption as well as fodder (Upadhyaya et al., 2014). The crop is valued for its drought tolerance (Dwivedi et al., 2012) short growth period and superior nutrition value (Saleh et al., 2013). In India, the crop is grown in Madhya Pradesh, Uttarakhand, Tamil Nadu, Andhra Pradesh, Karnataka, Maharashtra and Bihar. Barnyard millet has emerged as very important dual purpose feed and fodder crop. The grain can be consumed as whole grain or ground into flour which is used for porridge and various flat cakes or chapatis. Thus small millets are nutritionally rich staple food crop. But besides that they also provide good quality stover which is important for hill farming system, where fodder has become scarce in recent years. Little millet is rich in vitamin $B$, minerals like potassium, phosphorus, iron, zinc and magnesium. Therefore it can address nutritional sensitive agriculture, which aims at nutritional enhancement to combat the present scenario of micronutrient malnutrition
(Arunachalam et al., 2005; Kundgol et al., 2014; Selvi et al., 2015). In fact the stover of barnyard millet is one of the best in terms of nutritional quality among all the existing stovers. Barnyard millet grains are nutritious and as similar to other millets, it is also an appropriate food for patients intolerant to gluten causing celiac disease or other forms of allergies/ intolerance of wheat, as none of the millets are closely related to wheat, so they are appropriate foods for such patients. Seeds of the crop are very nutritious. Its grain contains 11.2

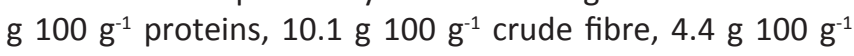

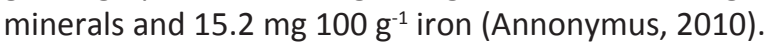

Assessment of genetic diversity in germplasm collection can facilitate classification and identification of diverse genotypes. Precise information on the nature and degree of genetic divergence helps the plant breeder in choosing the diverse parents for specific utilization in hybridization. In any crop improvement programme, once the variability is determined in germplasm and segregating population, the estimation of association among the traits is crucial in order to decide the selection criteria that improve yield components and nutritional traits. These may be variable in different segregating population. The F2 population of 
different crosses was studied to select the appropriate segregating population for further improvement (Laila et al., 2014). The present investigation done for increasing the yield potential and to identify superior source of divergent parents from distantly related clusters for suitable hybridization through genetic divergence analysis by using Mahalanobis $D^{2}$ statistics (Mahalanobis, 1936) in different genotypes of barnyard millet.

\section{Materials and Methods}

The present investigations were carried out during kharif, 2014 at the Research Block of Department of Crop Improvement and Seed Testing Laboratory of Department of Seed Science and Technology, College of Forestry, Ranichauri, Tehri Garhwal, Uttarakhand. The experimental materials for the present investigation comprised to 35 diverse germplasm of barnyard millet (Echinochloa spp.) including three checks viz., VL-172, VL-207 and PRJ-1 (a variety released from the Department of Crop Improvement, College of Forestry, Ranichauri). The experiment was conducted in the Randomized Block Design (RBD) design during first week of June under rainfed condition. Each of the entry was sown in two continuous rows of $3 \mathrm{~m}$ length in three replications with spacing of $22.5 \mathrm{~cm}$ within rows and $10 \mathrm{~cm}$ between the plants.

Observations were recorded on the basis of five randomly selected plants in each entry in each replication for fourteen morphological characters viz., days to 50 per cent flowering, days to maturity, plant height, number of productive tillers plant $^{-1}$, number of leaves on main tiller, flag leaf area, peduncle length, ear length, finger length, number of fingers ear $^{-1}$, biological yield plant ${ }^{-1}$, harvest index, 1000 seed weight and grain yield plant $^{-1}$. The genetic divergence in thirty five genotypes was estimated by Mahalanobis ' $\mathrm{D}^{2 \prime}$ statistics canonical variate analysis. Genotypes were grouped into a number of clusters according to the method given by Rao, 1952.

\section{Results and Discussion}

The existence of optimum genetic divergence between the parents is an important pre requisite for success of any crop improvement programme based on recombination breeding because crosses between genetically diverse parents have been found to be provided superior for trangrassive segregation in the segregating generations. $D^{2}$ statistics, a concept developed by Mahalnobis (1936) is important tool to plant breeder to classify the genotypes into different groups based on genetic divergence between them.

The 35 genotypes of barnyard millet were group into six different non-overlapping clusters as presented in Table 1 and Cluster III was highest number of 16 genotypes, followed by cluster II with 10 genotypes and cluster I with 6 genotypes. Cluster IV, V and VI were represented by only one genotype indicating wide diversity from set, as well as from each other. Earlier workers have also reported existence of substantial
Table 1: Clustering pattern of 35 genotypes of barnyard millet (Echinochloa frumentacea (Roxb.) Link) on the basis of genetic divergence

\begin{tabular}{lcl}
\hline $\begin{array}{l}\text { Clus- } \\
\text { ters }\end{array}$ & $\begin{array}{c}\text { No. of } \\
\text { genotypes }\end{array}$ & Genotypes \\
\hline I & 6 & $\begin{array}{l}\text { IEC-523, VL-239, PRB-802, IEC- } \\
566, T N A U-149\end{array}$ \\
II & 10 & $\begin{array}{l}\text { IC-543, IEC-411, EC-756, VL-232, PRB- } \\
\text { 401, IEC-111, PRB-904, IEC-546, RAU-2, }\end{array}$ \\
& & PRB-903 \\
III & 16 & $\begin{array}{l}\text { VL-182, PRB-9402, VL-172, VL-207, PRJ- } \\
\end{array}$ \\
& & $\begin{array}{l}\text { 1, VL-244, IC-542, RAU-11, EC-134192, } \\
\end{array}$ \\
IV & 1 & IEC-502, TNAU-155, IC-595, IEC-636, \\
V & 1 & VL-222 \\
VI & 1 & IEC-513 \\
\hline
\end{tabular}

genetic divergence by Shinde et al. (2013) and Suryanarayana et al. (2014) in finger millet, Anuradha et al. (2014) in barnyard millet and Nirubana et al. (2017) in kodo millet. The study indicated lack of any definite relationship or correlation between genetic diversity and geographical origin of the barnyard millet genotypes. This finding is conformity with the previous report advocating lack of parallelism between genetic and geographical diversity in finger millet by Wolie and Belete (2013), Surayanarayana et al. (2014); Negi et al. (2017).

The estimates of intra and inter cluster distances is represented by $D^{2}$ value have been given in Table 2 . Out of six clusters, cluster III had maximum intra cluster distance (14.59) followed by cluster II (11.97) and cluster I (7.46). This implies that these clusters have the genotypes with varied genetic architecture. The cluster IV, cluster V and cluster VI showed zero intra cluster distance due to monogenotypic nature. High intra-cluster genetic distance in cluster III was because of heterogeneous composition of that cluster. Collaborative results have also been given by Wolie and Belete (2013) and Negi et al. (2017).

Table 2: Intra and inter cluster distance $\mathrm{VD}^{2}$ values among 35 genotypes of barnyard millet (Echinochloa frumentacea (Roxb.) Link)

\begin{tabular}{lcccccc}
\hline Group & I & II & III & IV & V & VI \\
\hline I & 7.46 & 13.67 & 15.45 & 34.49 & 20.85 & 21.75 \\
II & & 11.97 & 24.20 & 41.62 & 26.15 & 27.11 \\
III & & & 14.59 & 32.95 & 28.78 & 37.92 \\
IV & & & & 0.00 & 53.83 & 79.00 \\
V & & & & & 0.00 & 22.90 \\
VI & & & & & & 0.00 \\
\hline
\end{tabular}


The maximum inter-cluster genetic distance was observed between cluster IV and VI (79.00) followed by cluster IV and $\mathrm{V}$ (53.83). The inter cluster between cluster II and cluster IV (41.62), cluster III and VI (37.92), cluster I and cluster IV (34.49) and cluster III and cluster IV (32.95) were also high. The clusters with higher inter-cluster distances indicated that the genotypes included in those clusters had high genetic variation and hybridization between genotypes of these cluster may result heterotic hybrids because of convergence of diverse genes scattered in parents to progeny. The minimum estimate for inter cluster distance was recorded between cluster I and II (13.67) and cluster I and III (15.45). The clusters with lowest inter-cluster distances indicated that genotypes present in these cluster pairs were genetically close to each other. The crosses between genotypes belonging to clusters separated by low inter cluster distance were likely to throw promising recombinants in the segregating generations. Similar results have also been proposed by Selvarani and Chandirasekaran (2000) and Anuradha et al. (2014) in barnyard millet. The intercluster distances were higher than the intra-cluster distances indicating the presence of wider genetic diversity between the clusters rather than within the clusters.

The intra-cluster group means for all fourteen characters are given in Table 3. Cluster I, having 6 genotype, showed highest cluster means for harvest index (10.36) and grain yield plant $^{-1}(4.40 \mathrm{~g})$ but, exhibited lowest cluster mean for days to

Table 3: Intra cluster group means for various components of barnyard millet (Echinochloa frumentacea (Roxb.) Link) genotypes

\begin{tabular}{|c|c|c|c|c|c|c|c|}
\hline \multirow[t]{2}{*}{ Sl. No. } & \multirow[t]{2}{*}{ Characters } & \multicolumn{6}{|c|}{ Cluster Means } \\
\hline & & 1 & II & III & IV & $\mathrm{V}$ & VI \\
\hline 1. & Days to $50 \%$ flowering & 52.67 & 52.93 & 53.19 & 55.33 & 56.33 & 58.00 \\
\hline 2. & Days to maturity & 131.67 & 130.57 & 131.90 & 130.33 & 131.33 & 133.00 \\
\hline 3. & Plant height $(\mathrm{cm})$ & 97.33 & 96.11 & 97.31 & 115.38 & 83.51 & 87.99 \\
\hline 4. & No. of productive tillers plant ${ }^{-1}$ & 2.92 & 2.91 & 3.00 & 3.00 & 3.13 & 2.60 \\
\hline 5. & No. of leaves on main tiller & 6.23 & 6.07 & 6.34 & 6.40 & 5.67 & 5.80 \\
\hline 6. & Flag leaf area $\left(\mathrm{cm}^{2}\right)$ & 37.44 & 35.74 & 34.35 & 46.05 & 37.40 & 31.92 \\
\hline 7. & Peduncle length $(\mathrm{cm})$ & 11.72 & 11.61 & 12.58 & 13.22 & 8.54 & 10.34 \\
\hline 8. & Ear length $(\mathrm{cm})$ & 16.03 & 15.80 & 15.98 & 16.99 & 16.48 & 15.80 \\
\hline 9. & Finger length $(\mathrm{cm})$ & 4.74 & 5.23 & 4.90 & 5.82 & 5.20 & 3.97 \\
\hline 10. & No. of fingers ear ${ }^{-1}$ & 16.25 & 13.40 & 16.46 & 15.97 & 18.31 & 16.15 \\
\hline 11. & Biological yield plant ${ }^{-1}(\mathrm{~g})$ & 42.64 & 36.04 & 46.23 & 49.33 & 47.20 & 35.13 \\
\hline 12. & Harvest index (\%) & 10.36 & 10.22 & 9.61 & 8.49 & 8.95 & 10.03 \\
\hline 13. & 1000 seed weight $(\mathrm{g})$ & 3.19 & 2.81 & 3.37 & 2.89 & 3.21 & 2.89 \\
\hline 14. & Grain yield plant $^{-1}(\mathrm{~g})$ & 4.40 & 3.67 & 4.40 & 4.20 & 4.22 & 3.55 \\
\hline
\end{tabular}

$50 \%$ flowering (52.67 days). Cluster II having 10 genotypes exhibited lowest cluster mean for ear length $(15.80 \mathrm{~cm})$, number of fingers per ear (13.40) and 1000 seed weight (2.81 g). Cluster III, having 16 genotypes exhibited highest cluster mean for 1000 seed weight $(3.37 \mathrm{~g})$ and grain yield per plant $(4.40 \mathrm{~g})$. The cluster IV having 1 genotype, resulting highest cluster mean for plant height $(115.38 \mathrm{~cm})$, number of leaves on main tiller (6.40), flag leaf area $\left(46.05 \mathrm{~cm}^{2}\right)$, peduncle length $(13.22 \mathrm{~cm})$, ear length $(16.99 \mathrm{~cm})$, finger length $(5.82 \mathrm{~cm})$ and biological yield plant ${ }^{-1}(49.33 \mathrm{~g}$ ) but, exhibited lowest cluster mean for days to maturity ( 130.33 days) and harvest index (8.49\%). The monogenotypic cluster $\mathrm{V}$ were responsible for highest cluster mean for number of productive tillers per plant (3.13) and number of finger ear ${ }^{-1}$ (18.31) but exhibited lowest cluster mean for plant height $(83.51 \mathrm{~cm})$, number of leaves on main tillers (5.67) and peduncle length $(8.54 \mathrm{~cm})$. Cluster VI, having 1 genotype exhibited highest cluster mean for days to $50 \%$ flowering ( 58.00 days) and days to maturity ( 133.00 days) but, exhibited lowest cluster mean for number of productive tillers (2.60), flag leaf area $\left(31.92 \mathrm{~cm}^{2}\right)$, ear length $(15.80 \mathrm{~cm})$, finger length $(3.97 \mathrm{~cm})$, biological yield plant ${ }^{-1}(35.13 \mathrm{~g})$ and 1000 seed weight $(2.89 \mathrm{~g})$.

On the basis of above results it is evident that cluster IV had maximum cluster means for most of desirable characters viz., plant height, number of leaves on main tiller, flag leaf area, peduncle length, ear length, finger length and biological yield per plant. Therefore, genotype VL-222 in this cluster can be used for improvement of grain yield and yield contributing characters, simultaneously. Similar results have also been obtained by Anuradha et al. (2014) in barnyard millet and Suryanarayana et al. (2014) in finger millet.

The relative contribution of different quantitative characters in (Table 4) depicted that finger length contributed maximum (28.91\%), towards genetic divergence followed by plant height (13.95\%), 1000 seed weight (12.10\%). Biological yield plant ${ }^{-1}$ 
Table 4: Contribution of different plant growth and grain yield characters to total divergence in barnyard millet (Echinochloa frumentacea (Roxb.) Link) genotypes

\begin{tabular}{|c|c|c|c|}
\hline SI. No. & Characters & NTPFR & PC \\
\hline 1. & Days to $50 \%$ flowering & 41 & 6.89 \\
\hline 2. & Days to maturity & 9 & 1.51 \\
\hline 3. & Plant height $(\mathrm{cm})$ & 83 & 13.95 \\
\hline 4. & No. of productive tillers plant ${ }^{-1}$ & 3 & 0.50 \\
\hline 5. & No. of leaves on main tiller & 22 & 3.70 \\
\hline 6. & Flag leaf area $\left(\mathrm{cm}^{2}\right)$ & 4 & 0.67 \\
\hline 7. & Peduncle length $(\mathrm{cm})$ & 49 & 8.24 \\
\hline 8. & Ear length $(\mathrm{cm})$ & 3 & 0.50 \\
\hline 9. & Finger length (cm) & 172 & 28.91 \\
\hline 10. & No. of fingers ear ${ }^{-1}$ & 18 & 3.03 \\
\hline 11. & Biological yield plant ${ }^{-1}(\mathrm{~g})$ & 52 & 8.74 \\
\hline 12. & Harvest index (\%) & 41 & 6.89 \\
\hline 13. & 1000 seed weight $(\mathrm{g})$ & 72 & 12.10 \\
\hline 14. & Grain yield plant $^{-1}(\mathrm{~g})$ & 26 & 4.37 \\
\hline
\end{tabular}

NTPFR: Number of times appearing first in ranking; PC: Per cent contribution (\%)

(8.74\%), peduncle length (8.24\%), days to $50 \%$ flowering $(6.89 \%)$, harvest index $(6.89 \%)$, grain yield plant ${ }^{-1}(4.37 \%)$, number of leaves on main tiller (3.70\%), number of fingers per ear (3.03\%) and days to maturity (1.51\%) exhibited low contribution towards genetic divergence, while remaining 3 character played negligently role less $(<1 \%)$ in contributing genetic diversity.

The low contribution was however measured on other characters, viz., flag leaf area $(0.67 \%)$, number of productive tillers plant ${ }^{-1}(0.50 \%)$ and ear length $(0.50 \%)$. These were considered to be the most important characters for the genetic diversity point of view. The observation is in conformity with the result obtained by Shinde et al. (2013), Suryanarayana et al. (2014); Devaliya et al. (2017); Patel et al. (2017) in finger millet.

The characters that appeared maximum number of times first, greater was its contribution towards genetic divergence. Among the characters plant height followed by grain yield per plant, ear length contributed maximum towards the total divergence (Suryanarayana et al., 2014).

\section{Conclusion}

Keeping in the view, inter-cluster genetic distance and cluster means, it could be concluded that the information for high inter cluster distances and cluster means could be useful for developing future hybridization program in the seek of heterotic hybrids in barnyard millet. Based on high inter-cluster distance of cluster IV with cluster VI, cluster IV with cluster $V$ and cluster II with cluster IV are recommended for further hybrid breeding programmes in mid hills of Uttarakhand.

\section{Acknowledgement}

The author sincerely acknowledges the College of Forestry, V. C. S. G. Uttarakhand University of Horticulture and Forestry, Ranichauri (Uttarakhand) for her M.Sc. research. Thanks are also due to the Head and Professor for providing research material, field and laboratory facilities at the Department of Seed Science and Technology, during the course of this investigation.

\section{References}

Annonymus, 2010. Millets: Future of food and farming. Millet Network of India. Deccan Development Society FIAN, India, 16.

Anuradha, N., Patro, T.S.S.K., Udaya Bhanu, K., Madhuri, J., Sowjanya, A., 2014. Multivariate analysis in barnyard millet (Echinochloa frumentacea (Roxb.) Link). International Journal of food, Agricuture and Veterinary Science 4(2), 194-199.

Arunachalam, V., Rengalakshmi, R., Kubera Raj, M.S., 2005. Ecological stability of genetic diversity among landraces of little millet (Panicum sumatrense) in south India. Genetic Resources and Crop Evolution 52(1), 15-19.

Devaliya, S.D., Singh, M., Intawala, C.G., 2017. Genetic divergence studies in finger millet [Eleusine coracana (L.) Gaertn.]. International Journal of Current Microbiology and Applied Sciences 6(11), 2017-2022.

Dwivedi, S., Upadhyaya, H., Senthilvel, S., Hash, C., Fukunaga, K., Diao, X., Santra, D., Baltensperger, D., Prasad, M. 2012. Millets: Genetic and Genomic Resources. Plant Breeding Review 35, 247-375.

Kundgol, N.G., Kasturiba, B., Math, K.K., Kamatar, M.Y., 2014. Screening of little millet landraces for chemical composition. International Journal of Farm Sciences $4(2), 33-38$.

Laila, F., Shah, F.S., Iqbal, S., Kanwal, M., Ali, S., 2014. Genetic variability studies in Brassica F2 populations developed through inter and intra-specific hybridization. Pakistan Journal of Botany 46(1), 265-269.

Mahalanobis, P.C., 1936. On the generalized distances in statistics. Proceeding of the National Institute of Sciences of India 2, 49-55.

Negi, S., Kumar, V., Bhatt, A., 2017. Genetic diversity among finger millet [Eleusine coranana (L.) Gaertn] genotypes for yield and its contributing traits. International Journal of Current Microbiology and Applied Sciences 6(8), 3332-3337.

Nirubana, V., Ganesamurthy, K., Ravikesavan, R., Chitdeshwari, T., 2017. Genetic diversity studies in kodo millet (Paspalum scrobiculatum L.) germplasm accessions based on biometrical and nutritional quality traits. 
International Journal of Current Microbiology and Applied Sciences 6(10), 832-839.

Patel, S.N., Patil, H.E., Popat, R.C., 2017. Genetic diversity study in finger millet (Eleusine coracana L.) genotypes: A multivariate analysis approach. International Journal of Pure and Applied Biosciences 5(5), 183-189.

Rao, C.R., 1952. Advanced Statistical method in Biometrical research. John Wiley and Sons, New York. pp. 374.

Saleh, A.S.M., Zhang, Q., Chen, J., Shen, Q., 2013. Millet Grains: nutritional quality, processing, and potential health benefits. Comprehensive Reviews in Food Science and Food Safety 12(3), 281-295.

Selvarani, M., Chandirasekaran, V.M., 2000. Genetic divergence and variability in barnyard millet (Echinochloa frumentacea). Annals of Agriculture Research 21(2), 212-215.

Selvi, M.V., Nirmalakumari, A., Senthil, N., 2015. Genetic diversity for zinc, calcium and iron content of selected little Millet Genotypes. Journal of Nutrition \& Food Sciences 5(6), 1. DOI: 10.4172/2155-9600.1000417.

Shinde, S.R., Desai, S.V., Pawar, R.M., 2013. Genetic diversity pattern in finger millet (Eleusine coracana (L.) Gaertn). Electronic Journal of Plant Breeding 4(3), 1242-1245.

Suryanarayana, L., Sekhar, D., Rao, N.V., 2014. Inter relationship and cause-effect analysis in Finger millet (Eleusine coracana (L.) Gaertn) genotypes. International Journal of Current Microbiology and Applied Science 3, 937-941.

Upadhyaya, H., Dwivedi, S., Singh, S., 2014. Forming core collections in barnyard, kodo and little millets using morpho-agronomic descriptors. Crop Science 54, 1-10.

Wolie, A., Belete, K., 2013. Genetic divergence and variability studies in some Ethiopian finger millet germplasm collections. Scholary Journal of Agriculture Science 3(4), 110-116. 